Revista de Dialectología y Tradiciones Populares, vol. LXXII, n. ${ }^{\circ}$ 1, pp. 37-42, enero-junio 2017 , ISSN: 0034-7981, eISSN: 1988-8457, doi: 10.3989/rdtp.2017.01.001.04

\title{
Representar la migración juvenil. Estudio comparativo de sus imaginarios simbólicos en la televisión y en las redes sociales digitales
}

\author{
Representing Youth Migration. Comparative Study of Its \\ Symbolic Imaginary on Television and Digital Social Networks
}

\author{
Joana Soto Merola ${ }^{1}$ \\ Universitat de Lleida \\ Mariona Visa Barbosa ${ }^{2}$ \\ Universitat de Lleida
}

\section{RESUMEN}

El artículo describe las dinámicas de creación de identidades que se fusionan entre las personas jóvenes que han emigrado a Londres en busca de trabajo. Se analizan los discursos y los imaginarios que se desprenden de los medios de comunicación generalistas y de las auto-representaciones que hacen los propios jóvenes de su éxodo. El objetivo del trabajo es entender cómo se negocia la identidad en un contexto mundial interconectado entre sí, arbitrado por las representaciones mediáticas y en el que el Estado-nación ha dejado de tener el monopolio de la construcción de las imágenes identitarias.

Palabras clave: Emigración; Identidad; Representación; Juventud; Televisión; Internet.

\section{SUMMARY}

This article describes the identity creation that emerges among young people who have emigrated to London searching for work. The discourse and imaginary arising from the general media and self-representations of young people are analysed, with a view to understanding how identity is negotiated in an interconnected global context, with media arbitration and where the nation state has lost its monopoly over the construction of images of identity.

Key words: Emigration; Identity; Representation; Youth; Television; Internet.

\footnotetext{
${ }^{1}$ Correo electrónico: Joana.soto1@gmail.com. ORCID ID: http://orcid.org/0000-0002-5416-6730.

${ }^{2}$ Correo electrónico: Marionavisa@filcat.udl.cat. ORCID ID: http://orcid.org/0000-0002-9261-264X.
} 


\section{INTRODUCCIÓN}

Considerando que los medios de comunicación son objetos de representación y de creación de identidades y, en consecuencia, tienen un papel relevante en la caracterización de las migraciones, proponemos el análisis de la representación de la emigración juvenil a Londres, en los programas informativos de las televisiones generalistas y en los videos que las personas migradas difunden a través de la red.

La investigación toma una actitud constructivista, a favor de la explicación de tipo social, y descarta que la identidad sea un producto natural, fruto de la introspección individual o de la esencia de una comunidad determinada. Varios autores (Appadurai 2001; Castells 2006) creen que la globalización ha modificado las dinámicas que se utilizan a la hora de definir la identidad. Martínez (2006) define la Modernidad en dos etapas diferenciadas. En la primera, para la construcción de su identidad, la gente recurría a unos pilares sólidos (trabajo, familia, nación y religión). Todos ellos tienden a debilitarse en la segunda Modernidad, que se caracteriza por un crecimiento de la globalización y una pérdida de pertenencia territorial.

En consecuencia, ante una cada vez más acelerada mundialización, en la que las fronteras de la libre circulación del capital se diluyen y el desplazamiento de personas aumenta, los términos globalización y territorialización deben ser repensados.

Asimismo, cabe decir que la juventud es un colectivo atractivo para los medios de comunicación. Ellos han contribuido a menudo a la difusión de imágenes descalificativas y de arquetipos estigmatizantes en torno a este fenómeno. Según afirman Figueras y Mauri (2010), en un 26\% de los casos en que las personas jóvenes aparecen como colectivo, este es representado de forma negativa. Otro elemento a tener en cuenta es que en un 78\% de los casos, las noticias sobre los jóvenes no tienen en cuenta las propias fuentes juveniles. La eclosión de las nuevas tecnologías de la comunicación puede contribuir a compensar esta tendencia negativizadora.

La metodología utilizada es el análisis de contenido, ya que permite describir los sistemas de valores y de representaciones sociales que se ocultan detrás de los mensajes. Utilizamos la imagen como fuente de información rica y relevante, entendida como un recurso imprescindible para las ciencias sociales. Se han explorado, por lo tanto, desde los elementos más técnicos, a los narrativos y todos aquellos referidos a la emigración y a los imaginarios simbólicos.

La selección de piezas informativas se ha hecho a partir de la búsqueda de noticias sobre la emigración a Londres en los buscadores de los portales informativos de TVE, TV3 y Telecinco. El resultado de la investigación nos ha proporcionado 10 piezas informativas repartidas en tres canales ${ }^{3}$.

\footnotetext{
${ }^{3}$ Comando actualidad: Limpiando cocinas en Londres; Dentistas en Lincoln (TVE 03/11/2010), Los jóvenes españoles vuelven a emigrar para encontrar empleo (TVE 03/02/2012), Comando actualidad: Emigrando por trabajo (TVE 3/9/2012), Londres ajuda a joves espanyols a buscar feina (TV3 04/02/ 2013), Las oportunidades llueven en Londres (Telecinco 02/06/2013), Artistas españoles buscan cumplir su sueño en Londres (Telecinco 01/08/2013), Els matins de TV3: Marxar fora per trobar un futur millor? (TV3 17/11/2014), Un albañil extranjero en Londres puede ganar hasta 1200 euros a la semana (TVE 10/12/2014), Más de 40.000 españoles emigran a Londres cada año en busca de empleo (Telecinco 13/12/2014), Valor afegit: Joves que no marxen (TV3 4-2-2015), No serà fácil: marxar de casa (TV3 3-03-2015) y Las españolas que triunfan en Londres enseñando (Telecinco 20/06/2015).
} 
Por lo que se refiere a los videos grabados y distribuidos por los propios jóvenes, la selección se ha hecho a partir de los documentales o de las webseries más vistas como One way ticket to London, Spaniards in London y La sorpresa.

\section{LA EMIGRACIÓN ES NOTICIA}

De las piezas informativas televisivas, destaca sobre todo su brevedad (las más cortas duran un minuto y las más largas no llegan a los 5). Esta circunstancia nos permite concluir que las telenoticias no son el espacio más propicio para profundizar en una temática tan compleja como la que supone el concepto de juventud.

Por lo que se refiere a los códigos visuales, gráficos y sonoros, se observa una diferencia significativa entre el tratamiento de las noticias en los canales públicos y privados. En el caso de Telecinco, dos de las cuatro noticias tienen un acompañamiento visual que permite un ritmo más dinámico. Los rótulos son informativos y aportan información sobre la persona que habla o hacen una breve explicación de la noticia y están presentes en 7 de cada 10 piezas.

Por otro lado, si nos fijamos en los referentes narrativos, las noticias se construyen sobre la experiencia personal de la emigración y son las televisiones públicas aquellas que en ocasiones ofrecen una mayor pluralidad en las voces narrativas. Sólo tres noticias han entrevistado a ingleses en sus piezas informativas.

En total, las noticias hablan de 35 historias personales. De estas, sólo 13 personas tienen trabajos cualificados y afines a su sector. Telecinco es el canal que muestra una tasa de éxito mayor, ya que de los 11 ejemplos que muestra, más de la mitad trabaja en aquello que quiere, mayoritariamente tareas artísticas o del sector de servicios.

Por otro lado, los motivos de la emigración en las piezas informativas de Telecinco obvian el desempleo, mientras que en el resto el paro aparece siempre como la causa principal del éxodo. TV3 expone una causa concreta de la partida de un universitario: la caída del presupuesto en investigación. Sólo en dos ocasiones, dos de los entrevistados reconocen haberse ido siguiendo su espíritu aventurero.

Los atributos otorgados a la emigración son positivos en 6 de los 10 casos, con descripciones como "a los británicos les encantamos", "si eres bueno en unos meses empiezas a subir como la espuma" (Telecinco 02/06/2013) o "el auge de la construcción en la capital inglesa donde todo son aguas, augura un crecimiento del empleo en el sector durante el 2015" (TVE 10/12/2014). El resto muestra declaraciones tanto positivas como negativas respecto a la emigración y ofrece un amplio abanico de experiencias: "Allí eres el nuevo y se ven en el derecho de chillarte" (TVE 17/07/2012) o "Aquí la vida no es fácil, no es como se pinta" (Telecinco 12/12/2014).

Comando Actualidad, de TVE, dedicó dos programas a la emigración en Londres. En el primer caso, ninguno de los entrevistados trabaja en aquello que ha estudiado. "Vivo al día, aquí", dice un piloto que lleva 20 días en Londres. "Tengo el peor trabajo que he tenido en mi vida" comenta un arquitecto técnico que trabaja en un restaurante. Por el contrario, el segundo reportaje sí muestra personas que han conseguido trabajos acorde con lo que han estudiado: "Aquí estoy fenomenal", comenta una de las dentistas que recientemente han emigrado a Londres. Del reportaje se desprende que el idioma y una oferta previa de trabajo son las claves del éxito. 
El programa No serà fàcil de TV3, centrado en la emigración a Escocia y Alemania; Salvados de La Sexta, con un programa dedicado a la emigración en Alemania y Comando Actualidad de TVE en el 2010 y el 2012, son los únicos que han dedicado un programa especial al tema. En otros programas, como Españoles en el mundo: Londres y Callejeros viajeros: Londres, no encontramos ninguna referencia explícita a la crisis ni al paro del Estado español. Los testimonios son descritos mayormente como triunfadores que han atrapado su sueño.

La simplicidad con que los medios de comunicación abordan los procesos migratorios contemporáneos contrasta con la complejidad con la que los jóvenes describen su exilio. Ellos no asumen de forma pasiva la representación externa y proponen una mirada propia a su situación, como podemos comprobar en One way ticket to London, Spaniards in London y La sorpresa.

La primera conclusión es la variabilidad de formas y narrativas que usan los jóvenes en su representación. One way ticket to London es un documental de unos treinta minutos que explica la experiencia de jóvenes, la mayoría licenciados, que viajan hasta la capital británica en busca del trabajo que, según ellos, ha dejado de existir en España. Spaniards in London es una miniserie donde se exponen las principales problemáticas de la migración. Finalmente, La sorpresa es un documental —a medio camino entre el videoclip y el relato más intimista- que denuncia el exilio forzoso de las personas que viven en la diáspora.

A pesar de la variabilidad formal, las tres producciones comparten un mismo relato: la migración de los jóvenes es vista como un exilio forzoso, consecuencia directa de la crisis económica española y de las acciones de los representantes políticos. Su interpretación de los hechos, pues, queda lejos de la narración de los medios de comunicación analizados. En este sentido, el documental La sorpresa denuncia explícitamente las explicaciones oficiales: "políticos, banqueros y empresarios especuladores han hecho que nuestro país no pueda darnos una oportunidad. Tenemos que volver a salir. Así que, a vosotros que nos negáis el futuro, os dedicamos estas lágrimas tan amargas".

El subtítulo de este documental es significativo y está dedicado a "todos los que están lejos". Esta expresión no sólo quiere ser un homenaje a todas aquellas personas expulsadas de sus casas, también se identifica con la comunidad imaginada (Anderson 1993), que une bajo un mismo paraguas todas aquellas personas que han emigrado en busca de trabajo.

Una interpretación similar ofrece One Way Ticket to London, un documental realizado por Borja Calvín y Clàudia Mateus, que recurre a las historias de vida para mostrar la realidad de la migración. Este trabajo se esfuerza por mostrar la importancia de las experiencias del viaje en primera persona, con relatos vivenciales que detallan la complejidad de la situación. Aparecen una decena de casos, la mayoría de los cuales definen la migración como un exilio forzoso causado por la situación económica de España. La práctica totalidad de las personas entrevistadas empieza a trabajar a las pocas semanas de llegar a Londres, pero lo hace en trabajos no cualificados, como hoteles, restaurantes o pubs. Los casos de éxito también quedan patentes en el documental, a pesar de ser una minoría. El video muestra el caso de personas jóvenes, formadas en varias disciplinas, como Pastora, "que ha decidido venir a Londres porque las cosas en España están fatal", o Javi, quien después de cinco meses de busca activa de trabajo, decidió trasladarse a Londres a probar suerte. 
Finalmente, Spaniards in London es una miniserie que detalla las primeras semanas de la migración, a través de la experiencia de cuatro jóvenes españoles. En los cinco primeros capítulos, los protagonistas muestran la realidad del emigrante, a través de la sátira: la soledad de los primeros días, el esfuerzo, la búsqueda de trabajo, el idioma, el ocio y el amor son los temas principales de esta ficción.

Estos tres productos coinciden en mostrar ciertos imaginarios comunes. El idioma, por ejemplo, es una de las claves que aparece a menudo en los relatos de los jóvenes, quienes afirman que su nivel de inglés no es suficiente. Este hecho se traduce en un obstáculo para conseguir el éxito. Las redes sociales también son una constante. La culminación del objetivo dependerá de la densidad del capital social de la persona migrada: los amigos o los conocidos representan la posibilidad de encontrar un lugar donde dormir, un contacto a quien preguntar o, simplemente, una compañía a quien recurrir.

Finalmente, sorprende que, en estos documentales, los relatos positivos de la emigración son pocos: el amor (el caso de una joven andaluza que se enamora de su compañero de piso) o el aprendizaje ("te salga bien o te salga mal, sacas algo de positivo", refiriéndose al idioma, al aumento de la autoestima, al trabajo y al tránsito hacia la vida adulta).

También resulta interesante tener en cuenta los miles de seguidores que tienen estos productos. Este hecho nos obliga a pensar que, tal vez, la ciudadanía busca informarse sobre la experiencia migratoria a través de los canales alternativos a los grandes medios.

\section{CONCLUSIÓN}

Si tenemos en cuenta la teoría del establecimiento de la agenda (McCombs y Shaw 1972), que considera que la percepción de los asuntos sociales está condicionada por la representación que de ella se hace en los medios de comunicación, vemos como la emigración no ha sido uno de los temas principales en la agenda informativa de los últimos años, a pensar del aumento de las tasas migratorias, a la vez que el marco conceptual bajo el que se ha interpretado deja fuera la búsqueda del origen del problema.

Las noticias de los medios de comunicación interpretan, en la mitad de los casos analizados, una visión amable y optimista del fenómeno, mientras que los jóvenes introducen en sus narrativas la frustración, la crisis y la dificultad del ser inmigrante. Las nuevas tecnologías facilitan que sean los jóvenes los que crean, difundan y consuman informaciones sobre sí mismos. La complejidad del relato es la clave interpretativa de estas piezas. La auto-representación ofrece una gran diversidad, tanto en el contenido como en la forma, y acostumbra a visibilizar la parte más negativa de la migración. 


\section{BIBLIOGRAFÍA CITADA}

Anderson, Benedict. 1993. Imagined Communities: Reflections on the Origin and Spread of Nationalism. México DF: Fondo de Cultura Económica.

Appadurai, Arjun. 2001. La modernización desbordada. Dilemas de identidad en el mundo contemporáneo. Buenos Aires: Ediciones Trilce.

Castells, Manuel (ed.). 2006. La sociedad red: una visión global. Madrid: Alianza Editorial.

Figueras, Mònica y Marcel Mauri. 2010. Mitjans de comunicació i joves. Anàlisi de la situació, mecanismes d'intervenció $i$ decàleg per a un tractament informatiu adequat per a les persones joves. Barcelona: Generalitat de Catalunya.

Martínez Sahuquillo, Irene. 2006. "La identidad como problema social y sociológico". Arbor. Ciencia, pensamiento y cultura CL XXXII 722: 811-824.

McCombs, Max y Donald Shaw. 1972. "The Agenda-Setting Function of Mass Media". Public Opinion Quarterly 36(2): 176-187. 